\title{
Behavior of Indian Peafowl Pavo cristatus Linn. 1758 During the Mating Period in a Natural Population
}

\author{
S. Harikrishnan, Karthikeyan Vasudevan* and K. Sivakumar \\ Wildlife Institute of India, P.O. Box 18, Dehradun 248001, Uttarakhand, India
}

\begin{abstract}
Behavioral observations on Indian peafowl Pavo cristatus in the Shivalik landscape of North India were carried out during their mating period, between 31 March and 21 May 2006. Behaviors of peafowl were recorded using scan samples. Overall, females, sub-adult males and adult males spent different proportions of time in different activities, and the proportion of time spent on different activities varied during the mating season. Visitation by females influenced the frequency of displays by adult male Indian peafowl during this period. The study reveals that peafowl behavior in its native habitat broadly conforms to that documented from captive and introduced populations. However, there were some differences between the wild and captive populations in vocalizations, maintenance behavior and spatial distribution of adult males. Since the time spent engaging in these behaviors may affect the cost of display, these results emphasize the need to assess the signaling cost in situ where the behavior evolved.
\end{abstract}

Keywords: Peafowl, breeding behaviour, exploded leks, time-activity budgets, in situ behaviour.

\section{INTRODUCTION}

The elaborate train and its display of the male Indian peafowl (Pavo cristatus), which is a visual signal directed at females, has long been a subject of fascination and debate in the scientific world. It is often used as a model for the study of animal signals and their evolution [1]. Several experimental and observational studies on captive populations of the Indian peafowl have advanced our understanding on the selection of ornamentation in males [2-7]. The available evidence indicates that the train of the male Indian peafowl could be expensive in terms of time spent in its maintenance [8]. Captive ornamental birds probably spend more time overall on maintenance behaviors than their wild counterparts because they are freed from the constraints of foraging and vigilance [8]. Therefore, the Indian peafowl may be expected to spend less time in maintenance activities such as preening the train in situ (natural), compared to those living in ex situ (captive/introduced) conditions. Further, behavioral observations of organisms in the field provide valuable insight into male 'quality', which is targeted by natural and sexual selection [9]. Therefore, in situ behavioral observations on such species are essential and should corroborate findings from captive populations.

Indian peafowl are reported to be polygynous [10], polyandrous [11] and have a 'lek' like mating system, where males defend small and clumped territories [12-14]. An 'exploded lek' mating system was reported from a population on Protection Island, Washington, USA, without any apparent territoriality among males [15]. A similar social organization was reported from its native habitat in India $[16,17]$. Sathyanarayana and Rathinasabapathy [18] further investigated the ecology and the activity patterns of the peafowl in southern India. The understanding of the evolution of mating systems in Indian peafowl largely pivots

*Address correspondence to this author at the Wildlife Institute of India, P.O. Box 18, Dehradun 248001, Uttarakhand, India; Tel: +91-135-264011; Fax:+91-135-2640117; Email: karthik@wii.gov.in on observations from captive populations or feral populations. This study documented the behaviors of Indian peafowl in its native habitat of India during the breeding season. The following questions are addressed in this study: (1) Are there differences in the proportion of time spent in major activities by adult males, sub-adult males and females of the Indian peafowl during daylight hours across the breeding season? (2) What is the pattern in the duration and frequency of displays during the breeding season? What factors can explain this pattern? (3) What is the spatial distribution of display courts and habitats used for display in the study area? We compared our findings from in situ with studies on captive and feral populations of the Indian peafowl and demonstrate the need to examine the behavior of the species in its native habitat.

\section{METHODS}

Our study area was located around the Khara river $\left(29^{\circ}\right.$ $54^{\prime} 3^{\prime \prime} \mathrm{N}$ to $29^{\circ} 54^{\prime} 57^{\prime \prime} \mathrm{N}, 78^{\circ} 16^{\prime} 8^{\prime \prime} \mathrm{E}$ to $78^{\circ} 16^{\prime} 37^{\prime \prime} \mathrm{E}$ ) which is south of the Shivalik ridge in Chilla range of Rajaji National Park, Uttarakhand, India (Fig. 1). It is characterized by hills ranging from 400 to $1000 \mathrm{~m}$ above mean sea level, which have steep south facing slopes drained by rivers running from north to south. There are three distinct seasons: winter (November-March), summer (April - June) and monsoon (July-October) and the temperature ranges from 10 to $45^{\circ} \mathrm{C}$. Rainfall in the area ranges from $1300 \mathrm{~mm}$ to 1900 $\mathrm{mm}$ annually, and during monsoon months (July-October), the rainfall is heavy. The rivers remain dry during winter and summer. The study area has northern Indian moist deciduous forests and northern tropical dry deciduous forests [19]. This area supports a sizeable population of Indian peafowl and a wide variety of predators on Indian peafowl [20].

We classified individuals of Indian peafowl into three categories: adult males, sub-adult males and females. We followed the classification of Johnsgard [21], but combined the first and second year males as sub-adults because of possible errors in assigning individuals to these two 
categories. We used the term "display court" as defined by Armstrong [22] to describe the site used by an adult male during display i.e., a small area that was defended by an adult male from other males and was used for keeping vigil and displaying.

The breeding season of the Indian peafowl is closely related to the monsoons, and therefore the timing in the year varies according to locality [23]. In our study area, displaying by males started in February and continued until the last week of May when the first rains stated in the region. Once a week we walked a $3 \mathrm{~km}$ length of the riverbed in the morning in order to record all the display courts in the study area. The centre of each display court was marked on a map using a GPS (Global Positioning System). Behavioral observations of Indian peafowl were made for 43 days between 31 March and 21 May 2006 by one observer (SH). Most observations were made at seven display courts, which were those that were most readily visible from a chosen vantage position, situated more than $50 \mathrm{~m}$ away from the closest displaying male. The birds were located at 05:30 h each day and observed until they disappeared into the forest. During mid-day the birds retreated into dense vegetation and were not observed. We resumed the observations at 15:00 h until the birds went to roost on trees. The seven different adult males were observed in their display courts continuously, females and sub-adult males were observed as they appeared in the area. The number of females and subadult males could not be enumerated because, individuals could not be identified. The density of peafowl in roughly $100 \mathrm{~km}^{2}$ of the study area was $6.5 \pm 3.7 \mathrm{~km}^{-2}$ [24].

We used instantaneous scan sampling to obtain a sample of behavioral states at pre-selected moments in time [25]. During each scan, the behavior of each visible individual (each individual in a scan gave one scan record each) was noted in turns. A scan was made after every five minute interval. Scans commenced once an Indian peafowl was seen and continued as long as at least one individual was visible. The percentage time spent in each of seven behavioral repertoire states (see below) was calculated cumulatively for each of the three categories of individuals. Duration of displays was measured during the scan sampling using a stopwatch timed as the period that the tail of the male was fanned. The duration of display was recorded independent of the scan samples.

In this study, ten common behaviors of peafowl were recorded; (1) feed, (2) stand, (3) walk, (4) run, (5) sit (6) display, (7) preen, (8) fight, (9) fly and (10) call. Other behaviors such as copulation, and aggressive behavioral events were also recorded through ad libitum observations. The description of behaviors followed Galusha and Hill [15] with the addition of 'fight', 'fly' and a modification of the definition of 'call', since Indian peafowl produce a variety of vocalizations. 'Fight' was recorded when two male Indian peafowl jumped in the air and tried to make contact with each other aggressively and used their legs to kick each other. 'Fly' was recorded when the birds flew. 'Call' was recorded when the Indian peafowl made a loud, sharp and repeated (up to six times in quick succession) vocalization, a single note of which sounds like "may-awe" [10]. Other vocalizations [23] were not recorded using scan sampling because they were of short duration. The proportion of time spent in each category of behaviors for each different category of individuals in each 'week' was quantified. We used the term 'week' to indicate a seven-day period during which observations were made everyday during morning and evening hours. The sixth 'week' alone had eight days of observations. Observations were terminated after this because of the onset of monsoon rains and a drastic reduction in the encounters of female groups.

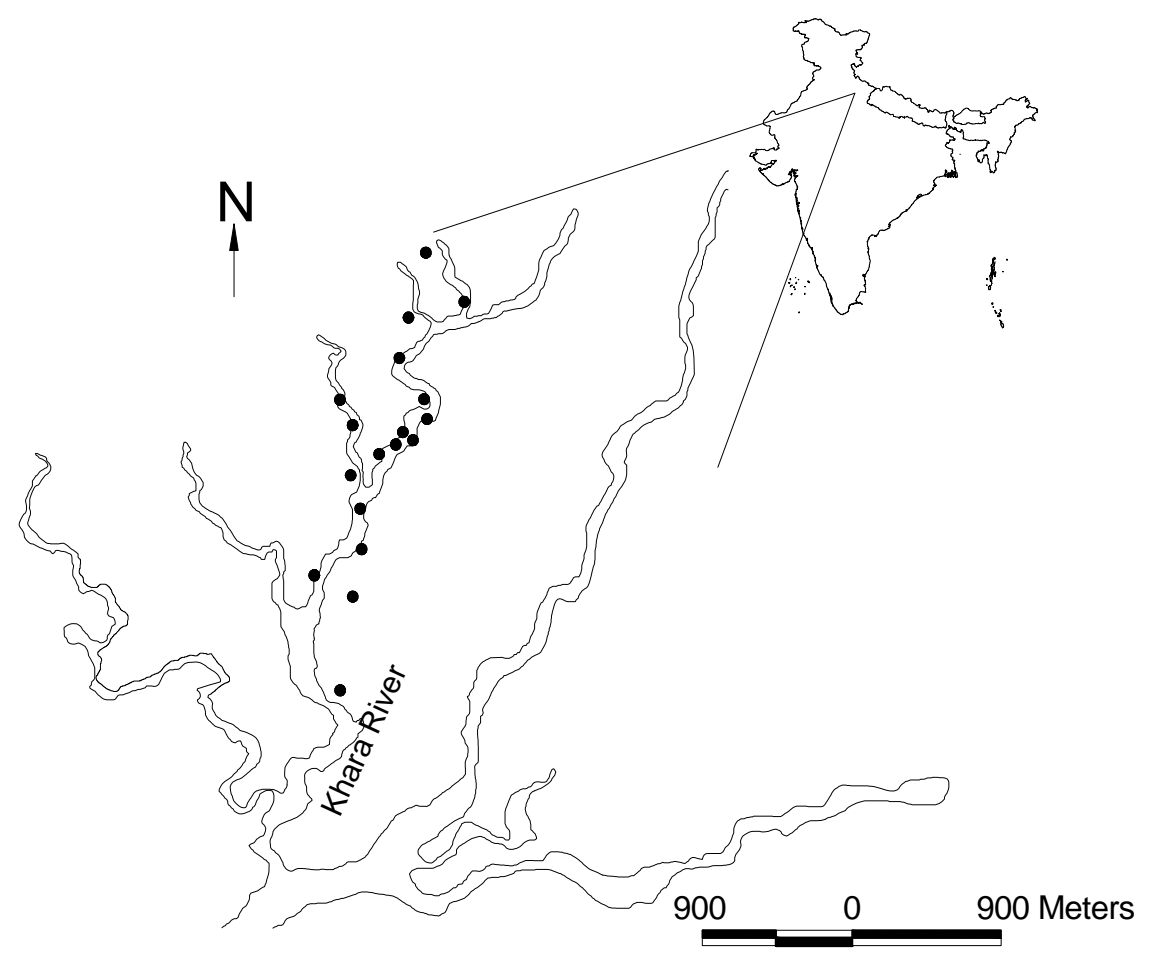

Fig. (1). The boundary of the study area around the Khara river with the display courts of adult males marked. 
The frequency of displays by the adult male Indian peafowl, the frequency of female scan records and the frequency of scans (measure of overall activity) in each day for 43 days were summarized. To test the hypothesis that the number of females present, measured as the frequency of female scan records, influenced the frequency of displays by the adult male Indian peafowl, independent of the overall activity of peafowl during the study period, we subjected the data to partial correlation. It is well known that autocorrelation is present in almost all real-world processes when sampled close enough in time [26]. In order to examine autocorrelation in the sequentially collected behavioral data we subjected these variables to lag correlations. We used Partial Autocorrelation Coefficients (PAC) for each variable using lag correlations with independence model in SPSS 14.0. The interval for the sequence of days was chosen when the Lag PAC value dropped below 95\% upper confidence limits in all three variables. The new data set had an interval of two days and a total of 15 days that did not show any autocorrelation was used for the analyses.

The habitat used by Indian peafowl was categorized as follows: (i) 'riverbed', which was rocky and dry throughout the period of study, with only a few scattered waterholes; (ii) open flat areas supporting short or tall grass with scattered trees termed 'grassland'. Occasionally, such areas had profuse growth of Cassia tora, a herb. The grassland bordered the course of the riverbed; (iii) 'Lantana thickets' bordered the grassland and were especially prominent on the base of steep slopes. This area was dominated by the exotic weed Lantana camara; (iv) 'Miscellaneous forest' surrounded the slopes around the valley and it had trees such as Terminalia tomentosa, Anogeissus latifolia, Mallotus philippensis and Cassia fistula.

We calculated the proportion of time spent in each category of behaviors for each category of individuals from our scan records. Proportion of time spent on different behaviors was tested for significant differences using a Chi square test for proportions [27]. The locations of display courts in the study area were marked on a map, and the nearest display court distance and the areas encompassing them were using a $95 \%$ minimum convex polygon around the court locations. This was done using ARC view, version 3.2.

\section{RESULTS}

\section{Observations Using Scan Sampling}

In all, 2088 scans were made, resulting in 6838 scan records, from $174 \mathrm{~h}$ of observation. After controlling for autocorrelation, the new data set had 753 scans and 2166 scan records. The maximum number of scans for any day was 62 and the minimum was 12 . The study recorded 10 behavioral states. These were examined for differences among adult males, sub-adult males and females. Feeding behavior differed significantly among the three categories of individuals (Table 1). Females spent most of the activity time in feeding, while adult and sub-adult males spent less time in feeding. Time spent in standing and walking showed a significant difference among the three categories (Table 1). Adult males spent most of the time standing in the display courts, whereas, sub-adult males and females spent greater amount of time walking than the adult males (Table 1). The proportion of time spent running, preening and calling also differed significantly among the three categories of individuals (Table 1).

For most behavioral categories, the occurrence frequency varied across the weeks. Adult males showed significant variations in the proportion of time spent in feeding, standing, walking, displaying and preening (Table 2). Subadult males also showed significant differences in the proportion of time spent in feeding, walking, and displaying. Females showed significant variation only in proportion of time spent in feeding and walking. Time spent by females in other activities did not show significant variation across the weeks (Table 2). The frequencies of displays by adult males, female scan records and the overall activity of the Indian peafowl showed a unimodal pattern with a peak between 19 and 28 days (Fig. 2). The frequency of displays by adult male Indian peafowl was correlated significantly with frequency of female scan records $(\mathrm{r}=0.67, \mathrm{~N}=15, \mathrm{P}<0.05)$ and the activity of peafowl, indicated by the total number of scans per day $(\mathrm{r}=0.75, \mathrm{~N}=15, \mathrm{P}<0.05)$. The frequency of female scan records was weakly correlated with activity of the peafowl $(\mathrm{r}=0.51, \mathrm{~N}=15, \mathrm{P}=0.05)$. The frequency of displays by adult male Indian peafowl and the frequency of female scan records were correlated significantly even after controlling for the effect of peafowl activity (partial correlation coefficient $\mathrm{r}=0.62, \mathrm{df}=13, \mathrm{P}<0.05)$. The mean display duration for the adult male Indian peafowl recorded from 32 displays was $430.03 \pm 34.29$ seconds with a maximum of 1060.00 seconds, and a minimum of 28.50 seconds. The median display duration was 384.85 seconds. The display duration was not influenced by mean number of females per scan during the breeding season $(\mathrm{r}=-0.04, \mathrm{P}>$ $0.05, \mathrm{~N}=32$ ). We observed five copulations performed by four different adult males, and all of them occurred in the second half of the study period.

Table 1. Percent Activity Time Allocated for Activities Performed by Indian Peafowl from 31 March to 21 May 2006 During the Breeding Season. A Non-Parametric Chi-Square Test for Proportions was Performed to Analyze Differences between Adult Males, Sub-Adult Males and Females in the Allocation of Activity Time for Different Activities. *Indicates $P<0.05$

\begin{tabular}{|c|c|c|c|c|c|c|c|c|c|c|}
\hline & Feed & Stand & Walk & Run & Sit & Display & Fight & Preen & Call & Fly \\
\hline Adult males & 25.93 & 37.90 & 13.86 & 0.20 & 0.20 & 16.70 & 0.18 & 2.02 & 2.89 & 0.12 \\
\hline Sub-adult males & 41.08 & 28.05 & 26.69 & 0.04 & 0.27 & 1.91 & - & 1.18 & 0.18 & 0.27 \\
\hline Females & 54.99 & 20.85 & 21.97 & 0.80 & 0.18 & - & 0.15 & 0.72 & 0.07 & 0.29 \\
\hline$\underset{d f=2}{\chi^{2}}$ & $543.98^{*}$ & $214.4^{*}$ & $117.07^{*}$ & $12.07^{*}$ & 0.33 & - & - & $18.96^{*}$ & $101.35^{*}$ & 2.5 \\
\hline
\end{tabular}




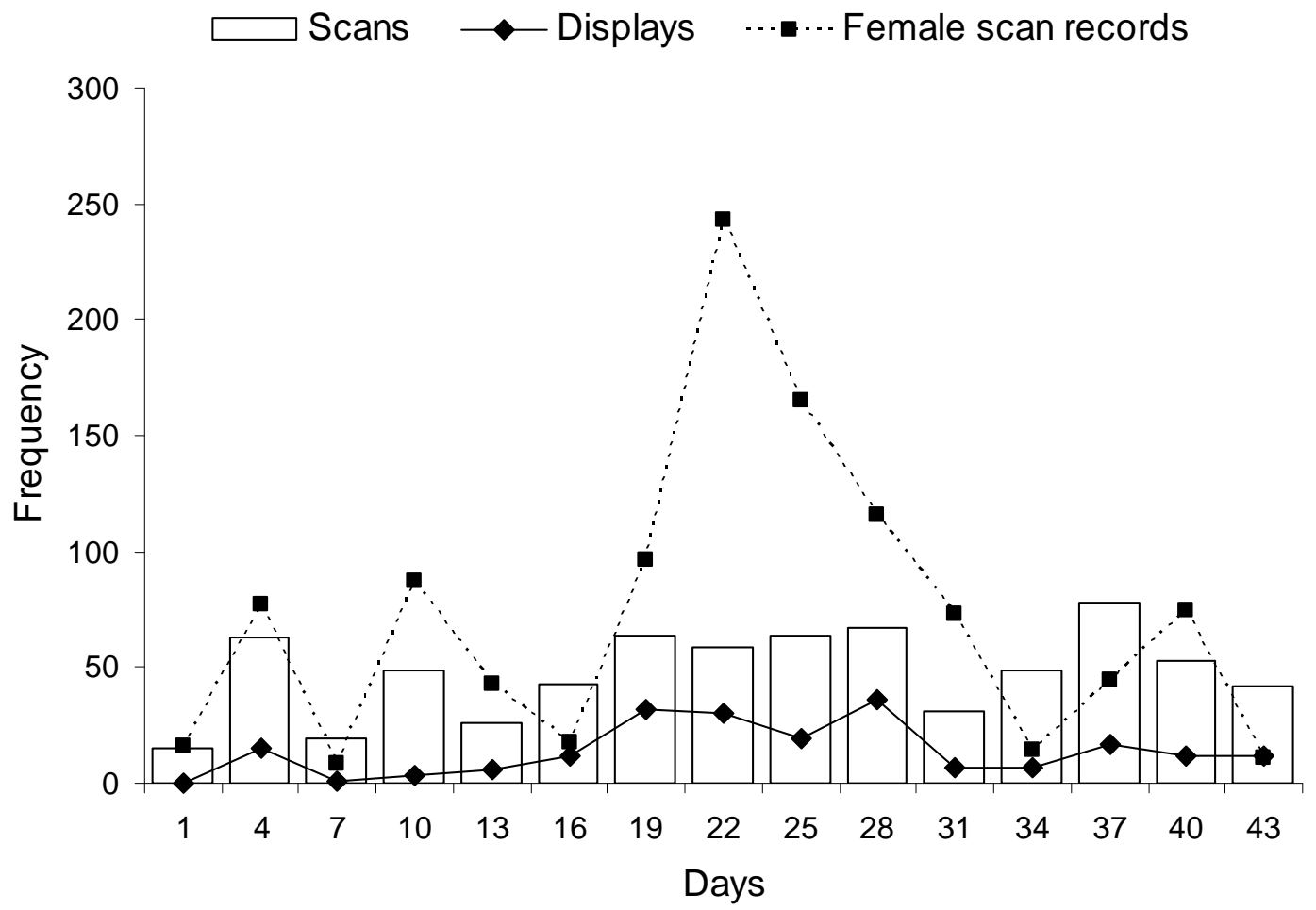

Fig. (2). The relationship between the frequency of displays by adult males, the number of female observations and the total number of scans for Indian peafowl in Rajaji National Park, India.

Table 2. Percent Activity Time Allocated for Major Behaviors by Indian Peafowl in Six Weeks from 31 March to 21 May 2006 During the Breeding Season Using Instantaneous Scan Sampling. 'N' Refers to the Number of Scan Records Used to Arrive at the Percent Time Allocation. Non-Parametric Chi-Square test for Proportions was Performed to Analyze the Difference in Time Allocation for Different Activities Across Six Weeks between Adult Males, Sub-Adult Males and Females. * Indicates $P<0.05$

\begin{tabular}{|c|c|c|c|c|c|c|c|c|c|c|c|c|c|c|c|c|c|c|}
\hline \multirow{2}{*}{ Weeks } & \multicolumn{6}{|c|}{ Adult Males } & \multicolumn{6}{|c|}{ Sub-Adult Males } & \multicolumn{6}{|c|}{ Females } \\
\hline & $\mathbf{N}$ & Feed & Stand & Walk & Display & Preen & $\mathbf{N}$ & Feed & Stand & Walk & Display & Preen & $\mathbf{N}$ & Feed & Stand & Walk & Display & Preen \\
\hline 1 & 292 & 26.03 & 38.70 & 19.52 & 12.67 & 3.08 & 71 & 30.99 & 32.39 & 35.21 & - & 1.41 & 254 & 57.09 & 19.69 & 23.23 & - & - \\
\hline 2 & 203 & 24.14 & 32.51 & 22.17 & 16.26 & 4.93 & 145 & 50.35 & 31.72 & 13.79 & 4.18 & - & 362 & 64.09 & 17.40 & 17.96 & - & 0.55 \\
\hline 3 & 498 & 18.89 & 43.81 & 12.70 & 22.64 & 1.95 & 102 & 23.53 & 22.55 & 47.06 & 3.92 & - & 461 & 52.93 & 20.39 & 26.46 & - & 0.22 \\
\hline 4 & 542 & 25.04 & 34.30 & 13.69 & 25.45 & 1.52 & 399 & 38.85 & 32.58 & 25.56 & 1.00 & 2.01 & 829 & 55.13 & 23.04 & 20.51 & - & 1.33 \\
\hline 5 & 713 & 36.05 & 39.97 & 11.92 & 11.08 & 0.98 & 142 & 45.07 & 30.99 & 21.83 & 0.07 & 1.41 & 351 & 48.72 & 24.22 & 26.78 & - & 0.03 \\
\hline 6 & 618 & 23.95 & 44.98 & 15.53 & 13.59 & 1.94 & 169 & 44.97 & 23.08 & 31.36 & 0.59 & - & 234 & 55.13 & 16.24 & 26.92 & - & 1.71 \\
\hline $\begin{array}{c}\chi^{2} \\
\text { (df) }\end{array}$ & & $\begin{array}{c}55.35^{*} \\
(5)\end{array}$ & $\begin{array}{c}24.83^{*} \\
(5)\end{array}$ & $\begin{array}{c}21.84^{*} \\
(5)\end{array}$ & $\begin{array}{c}74.43^{*} \\
(5)\end{array}$ & $\begin{array}{c}15.71 * \\
(5)\end{array}$ & & $\begin{array}{c}23.80^{*} \\
(5)\end{array}$ & $\begin{array}{c}8.28 \\
(5)\end{array}$ & $\begin{array}{c}39.92 * \\
(5)\end{array}$ & $\begin{array}{c}20.79^{*} \\
(4)\end{array}$ & $\begin{array}{c}0.28 \\
(2)\end{array}$ & & $\begin{array}{c}18.85^{*} \\
(5)\end{array}$ & $\begin{array}{c}10.68 \\
(5)\end{array}$ & $\begin{array}{c}16.11 \\
* \\
(5)\end{array}$ & - & $\begin{array}{c}8.20 \\
(4)\end{array}$ \\
\hline
\end{tabular}

Displays by adult males were recorded in 572 scan records. Fifty one percent of displays were on riverbeds. Grasslands were used in $43 \%$, Lantana thickets in $6 \%$ and miscellaneous forests in $<1 \%$ of the displays. We identified eighteen display courts of adult males. The courts were located on either side of the riverbed. Display courts typically had a raised area, such as a mound or fallen tree or a large rock on which the adult male stood and kept vigil on approaching females. The mean nearest inter-court distance was $716.83 \pm 36.62 \mathrm{~m}$. The area encompassed by the eighteen display courts was 75 ha and the density of display courts was 0.24 per ha.

For some of the major behaviors, the time activity budget of the adult male was compared with previous studies (Table 3). This table is a modified version of the one provided by Walther [28]. The percent time spent in displaying and preening by the adult male differed from previous studies mainly on introduced populations. 
Table 3. A Comparison of \% Time Spent in Different Activities by Male Indian Peafowl as Recorded in Different Studies. a - Ridley et al. [30], b - Walther [28], c - Sathyanarayana and Rathinasabapathy [18], d the Present Study

\begin{tabular}{|c|c|c|c|c|}
\hline \multirow{2}{*}{ Behavior } & \multicolumn{4}{|c|}{ \% Time Budget } \\
\cline { 2 - 5 } & \multicolumn{2}{|c|}{ Ex-Situ } & \multicolumn{2}{c|}{ In-Situ } \\
\cline { 2 - 5 } & $\mathbf{a}$ & b & c & d \\
\hline \hline Displaying & 8.40 & 7.20 & 1.20 & 16.70 \\
\hline Calling & 4.20 & 0.20 & 0.50 & 2.98 \\
\hline Feeding & 38.50 & 25.30 & 37.30 & 25.93 \\
\hline Standing & 23.50 & 31.00 & - & 37.9 \\
\hline Walking & - & 2.10 & 19.10 & 13.86 \\
\hline Preening & - & 14.90 & 11.80 & 2.02 \\
\hline
\end{tabular}

\section{Ad libitum Observations}

Ad libitum observations revealed that adult males defended a very small portion, (ca. $400 \mathrm{~m}^{2}$ ) of the home range as their display court. Five out of the seven intensively observed display courts had very small water bodies. Adult males stood on top of any raised substrate with their neck extended. In this position, they turned their head from side to side frequently and produced loud 'may-awe' calls that were repeated in quick succession. They exhibited aggressive behavior towards sub-adult males by forward lunges directed at them on certain occasions. Between adult males, fights occurred when one of them moved within less than ca. $20 \mathrm{~m}$ distance from the display court of another. The males jumped up in the air facing each other, vigorously fluttered their wings and kicked each other with their spurs. The fights were always interspersed with ritualized aggression, where the birds raised their trains at an angle away from the ground without spreading them and walked parallel to each other, shoulder to shoulder. They reciprocated this 'ritualized aggression' and often they walked back and forth repeatedly, intermittently pecking on the ground. This continued for several minutes until one of the males moved away from the area. During the study period, four extended fights were recorded in the first two weeks of the study. Five instances of aggressive behavior (forward lunges) were recorded. We also observed the adult males of the Indian peafowl feeding next to each other without any territorial behavior. Mating commenced when the male lunged forward after displaying, to mount the female once it crouched. The male dropped the train during copulation and held the crest plumes of the female with its beak. In this position, the male made a highpitched whistling call as reported by Galusha and Hill [15]. After copulation, which lasted a few seconds, adult males remained in their courts displaying to other females and never attempted to follow the female they mated.

\section{DISCUSSION}

The behavior of Indian peafowl was strongly influenced by age and sex. Adult males spent only about half as much time as females in feeding. This could be attributed to greater amount of time spent standing, displaying and preening by adult males than by females. Adult males spent significantly more time in preening than sub-adult males and females suggesting they incurred a 'high maintenancehandicap' because of the elaborate ornamentation [8]. Subadult males, which lack the long train but possess the iridescent plumage similar to that of the adult males, were observed to spend about half the time spent by the adult males in preening (but see, [29]). We infer that a long train in adult males probably involves about a two-fold increase in time allocated for maintenance and that this extra time allocated is solely for the maintenance of the long train in adult males. Reduced feeding and increased display and maintenance activities are energetically costly for a male, and therefore, ensure that only the fittest males are able to keep vigil and display for long periods of time, resulting in greater mating success. Standing is an important behavioral state for a predominantly ground living bird like Indian peafowl, as it enables the bird to invigilate and locate threats from a distance [15]. This posture probably enabled the adult males to locate groups of females from a distance. This posture in adult males was associated with calling, which made them conspicuous, and probably signaled their location. Sitting was a rare event in our scan records perhaps because of the time intervals chosen for observations, when the Indian peafowl is most active and observations could be made on them. It is likely that during the middle of the day the Indian peafowl performed resting and other maintenance activities. Among sub-adult males, the most common activity was feeding, followed by standing and walking. Although adult males, sub-adult males and females performed preening and calling, adult males spent significantly more time on these behaviors than sub-adult males and females. The time spent calling by adult male Indian peafowl in situ $(2.89 \%)$ was comparable to $<2 \%$ from Protection Island, USA [15] and 3-8.5\% from Whipsnade Park, UK [30]. Adult males used several variations of the call, as described by Johnsingh and Murali [23]. Calls are signals directed at other individuals, which may not be within sight, and probably contain information on the fitness of the caller. The frequency of calling might influence female visitation, and thereby influence the breeding success of the caller. Studies on sexual selection in Indian peafowl have so far concentrated mainly on visual signals $[6,7,15]$ (but see, $[14$, 17]). Calling may also be expensive in situ because it makes the caller vulnerable to predation. We suggest that calling, the loss of feeding time due to long periods vigilance and displaying, should be taken into consideration when the cost of male peafowl advertisement is measured.

We documented a unimodal pattern in the frequency of displays by the adult males, the frequency that females were observed and the activity of the Indian peafowl. All these variables were also correlated with each other. The unimodal pattern could have resulted due to two constraints that acted upon the observations made during this study: (i) reduced daylight period constrained our observations on adult females and males at the beginning of the breeding season; (ii) the increased breeding activity resulted in less number unmated females towards the end of the study period. The frequency of display by the adult males increased with increase in female visitation at the display courts because, displaying is energetically costly for the male. 
This study constitutes the first in situ documentation of the degree of dispersion of adult males in the Indian peafowl. Ad libitum observations suggest that adult male Indian peafowl maintained small display courts and defended them as if these were miniature territories. Females in groups visited these display courts during the breeding season causing heightened displaying activity in adult male Indian peafowl in the study area. Inter-court distances from this study are far greater than previously reported $[3,15]$. Adult males of the Indian peafowl were observed feeding next to each other without any territorial behavior, while females were not present or away from the display courts. This suggests that aggression among adult males of the Indian peafowl probably occurs only when they are displaying. There is evidence that peafowl lek organization is affected by non-defendable resources [14] such as food. We hypothesize that the distribution of resources such as water holes affected the distribution of display courts by adult male Indian peafowl. Since the number of encounters between lekking males is inversely proportional to the distance between them, instances of fights between lekking males in case of exploded leks should be lower than that in classical leks [31]. We documented only six instances of fighting between adult males, four of which happened in the first two weeks of the study. In a classical lek mating system, 30 instances of fights between adult males of the Indian peafowl were reported [3]. We hypothesize that male-male fights influence spacing of adult males in situ. Our observations on the spatial distribution of display courts agree with the description of the 'exploded lek' [32]. Adult males more frequently used riverbeds and grasslands for displaying than Lantana thickets or miscellaneous forests. We attribute this to; (1) presence of water holes (2) increased visibility of adult males in open habitats such as the riverbeds and the grasslands (3) increased visibility combined with aggregation of females and sub-adult males resulting in reduced risk of predation.

Our data from the natural population suggests that only about $2 \%$ of the time was spent on preening. This is much lower than the percent time recorded in previous studies (Table 3). The observed difference between natural and introduced populations in time allocated for preening was an artifact of sampling, because we could not observe the birds during mid day hours as they retreated into dense vegetation. However, the differences observed in time allocated for other activities deserve different explanations. The time spent displaying by adult males (16.70\%) in situ (this study) was much higher than that reported from captive populations [30]. The median display duration was also much longer than that reported from a free ranging population [15]. These differences cannot be tested statistically because the data were collected using different sampling methods and the raw data is not available for comparisons. .However, similar differences between captive and wild populations in time allocated to maintenance activities have been reported for many other species of birds [8]. We believe that the increase in displays and the duration of display was probably related to the high density of peafowl in the river bed area were the observations were made. The lesser amount of time spent in feeding compared to other studies is probably due to high female visitation rate observed in this study.
The Indian peafowl behavior in its native habitat broadly conforms to those documented from captive and introduced populations. However, there are some differences in the time spent in body maintenance, vocalizing and in the spatial distribution of display courts during the breeding season. Irrespective of the overall activity during the breeding season, visitation by females in the core habitat influenced the frequency of display by the adult male Indian peafowl. We suggest that studies on the behavior of the Indian peafowl should re-assess signaling cost by adult males to better understand how sexual selection operates in this species. Our study emphasizes the need to carry out detailed investigations in the habitats where the behaviors of interest evolved.

\section{REFERENCES}

[1] Gadagkar R. Is the peacock merely beautiful or also honest? Curr Sci (Bangalore) 2003; 85: 1012-20.

[2] Manning JT. Age-advertisement and the evolution of the peacock's train. J Evol Biol 1989; 2: 379-84.

[3] Petrie M, Halliday T, Sanders C. Peahens prefer peacocks with elaborate trains. Anim Behav 1991; 41: 323-31.

[4] Petrie M. Peacocks with low mating success are more likely to suffer predation. Anim Behav 1992; 44: 585-6.

[5] Petrie M. Improved growth and survival of offspring of peacocks with more elaborate trains. Nature 1994; 371: 598-9.

[6] Petrie M, Halliday T. Experimental and natural changes in the peacock's train can affect mating success. Behav Ecol Sociobiol 1994; 35: 213-7.

[7] Petrie M, Cotgreave P, Stewart I. Variation in the train morphology of the peacocks. J Zool 1996; 238: 365-71.

[8] Walther BA, Clayton DA. Elaborate ornaments are costly to maintain: evidence for high maintenance handicaps. Behav Ecol 2005; 16: 89-95.

[9] Irschick DJ, Herrel A, Vanhooydonk B, Damme RV. A functional approach to sexual selection. Funct Ecol 2007; 21: 621-6.

[10] Ali S, Ripley DS. Handbook of the birds of India and Pakistan. Oxford University Press: UK 1969.

[11] Lank DB, Smith CM, Hanotte O, Ohtonen A, Bailey S, Burke T. High frequency polyandry in a lek mating system. Behav Ecol 2002; 13: 209-15.

[12] Hillgarth N. Social organization of wild peafowl in India. J World Pheasant Assoc 1984; 9: 47-56.

[13] Rands MRW, Ridley MW, Leliott AD. The social organization of feral peafowl. Anim Behav 1984; 32: 830-5.

[14] Loyau A, Jalme MS, Sorci G. Non-defendable resources affect peafowl lek organization: a male removal experiment. Behav Proc 2007; 74: 64-70.

[15] Galusha Jr, JG, Hill Jr, LM. A study of the behavior of Indian peacocks (Pavo cristatus) on protection island, Jefferson County. Washington, USA: Pavo 1996; vol. 34: pp. 23-31.

[16] Sharma IK. Social and sexual behavior of peafowl. Environ Aware 1978; 1: 169-71

[17] Yasmin S, Yahya HAS. Correlates of mating success in Indian peafowl. Auk 1996; 113: 490-2.

[18] Sathyanarayana MC, Rathinasabapathy B. Notes on the feeding ecology and activity patterns of the blue peafowl. J World Pheasant Assoc 1990-92; 15 \& 16: 97-101.

[19] Champion HG, Seth SK. A revised survey of the forest types of India. New Delhi: Government of India Press 1968.

[20] Osmaston BB, Sale JB. Wildlife of Dehra Dun and adjacent hills. Dehra Dun: Natraj Publishers 1989.

[21] Johnsgard PA. The Pheasants of the world. Oxford: Oxford University Press 1986

[22] Armstrong AA. Bird display and behavior: an introduction to the study of bird psychology. England: Lindsay Drummond Ltd 1947.

[23] Johnsingh AJT, Murali S. The ecology and behavior of indian peafowl Pavo cristatus Linn. of Injar. J Bombay Nat Hist Soc 1980; 75: 1069-79. 
[24] Harihar A, Pandav B, Goyal SP. Responses of tiger (Panthera tigris) and their prey to removal of anthropogenic influences in raja ji national park, India. Eur J Wildl Res 2009; 55: 97-105.

[25] Altmann J. Observational study of behavior: sampling methods. Behavior 1973; XLIX: 227-67.

[26] Jassby AD, Powell TM. Detecting changes in ecological time series. Ecology 1990; 71: 2044-52.

[27] Gibbons JD. Nonparametric statistical inference. New York: McGraw-Hill Inc. 1971

[28] Walther BA. Do peacocks devote maintenance time to their ornamental plumage? time budgets of male blue peafowl. Pavo cristatus Lundiana 2003; 4: 149-54.
[29] Galusha JG, Redd JM. Population structure and daytime behavior of indian peafowl (Pavo cristatus) on protection island, Jefferson County, Washington. Pavo 1992; 30: 75-86.

[30] Ridley MW, Lelliott AD, Rands MRW. The courtship display of feral peafowl. J World Pheasant Assoc 1983-84; 9: 57-68.

[31] Foster MS. Disruption, dispersion, and dominance in lek-breeding birds. Am Nat 1983; 122: 53-72.

[32] Johnsguard PA. Arena birds: sexual selection and behavior. Washington DC: Smithsonian Institution Press 1994.

(C) Harikrishnan et al.; Licensee Bentham Open.

This is an open access article licensed under the terms of the Creative Commons Attribution Non-Commercial License (http://creativecommons.org/licenses/by$\mathrm{nc} / 3.0 /$ ), which permits unrestricted, non-commercial use, distribution and reproduction in any medium, provided the work is properly cited. 